\title{
Ssciendo
}

DOI: $10.2478 / \mathrm{adms}-2021-0012$

\author{
Hamza Khalid, A.A. Gomez-Gallegos* \\ Glasgow Caledonian University, Department of Mechanical Engineering, School of Computing, \\ Engineering and Built Environment, Cowcaddens Road, Glasgow, G40BA \\ *ares.gomez@gcu.ac.uk
}

\section{SUBSTITUTING Ti-64 WITH AA2099 AS MATERIAL OF A COMMERCIAL AIRCRAFT PYLON}

\begin{abstract}
The aircraft industry is striving to reduce the weight of aircraft to save fuel and hence reduce total cost. New alloys and composites with properties such as low weight and high strength are continuously developed. Titanium alloys have the best strength-to-weight ratio among metals which makes them very suitable for aircraft applications. Ti-64 is the most common Titanium alloy used in aircraft. AA2099 is a 3rd generation Al-Li alloy and has the lowest density among all Aluminium alloys making it very attractive for aircraft applications. Pylons of commercial aircraft are currently made primarily with Ti-64 and this study focused on the replacement of Ti-64 with AA2099. Loading conditions, operating temperature, corrosion resistance, manufacturability and recyclability of the pylon were analysed of both Ti-64 and AA2099. Three critical scenarios were chosen for the loading conditions of the pylon. These were simulated using finite element analysis first using Ti-64 and then AA2099. From the results, it is evident that using AA2099 as the material of the pylon instead of Ti-64 offered weight savings. The operating temperature, manufacturability and recyclability also showed advantages when using AA2099 whereas corrosion factors favoured Ti-64, since AA2099 was found to be very prone to galvanic corrosion.
\end{abstract}

Keywords: Ti-6Al-4V; AA2099; Al-Li; Aircraft; Pylon; FEA

\section{INTRODUCTION}

In the manufacturing of commercial aircraft, both the cost-efficiency and properties of the materials used are crucial. One of the main criteria of material selection in this industry is the amount of weight savings a material can offer. Improvement in different mechanical properties including lowering the density, increasing the strength or increasing the stiffness of a material can contribute to weight savings; although, lowering the density of a material results in the most weight savings [1].

Overall, steels offer the highest strengths for commercial metallic structures. Particularly, steel has been used in aircraft for the manufacturing of landing gears, flap tracks, and actuation components and systems. High-strength low-alloy (HSLA) steel, 4340M (or 300M), with a minimum tensile strength of $1930 \mathrm{MPa}$ and a toughness of $60 \mathrm{MPa}$ per square meter was used for 
most of the landing-gear structures prior to the 1990s [2]. As the aircraft requirement increased, alloys AerMet 100 and AerMet 310, by Carpenter Technology Corporation (Carpenter), were developed. The latest, with a $2000 \mathrm{MPa}$ ultimate strength and a minimum toughness above 110 MPa per square meter, has been used for landing gears of US Navy aircraft since 2000. However, both lack corrosion resistant properties which limits their applicability [2]. Stainless steels (SS) are also used on airframes, but they are usually limited by their strength. In the las two decades, the use of SS has been increasing with the development of higher-strength grades. For example, Custom 465, also from Carpenter, has been heat-treated to ultimate tensile strengths of 1655$1795 \mathrm{MPa}$ and "true" stainless steel characteristic. Despite the high weight characteristic of the steels, Custom 465 is now used by major aircraft manufacturers worldwide for the manufacturing of torque tubes, pneumatic cylinders, braces, struts, fuse pins, and flap tracks [2].

Titanium alloys, having the highest strength-to-weight ratio among metals, are very suitable for applications in aircraft [3]. One of the earliest alloys of Titanium is Ti-6Al-4V, more commonly known as Ti-64 [4]. Ti-64 has an ultimate strength of $900 \mathrm{MPa}$ with toughness extending between $55 \mathrm{MPa}$ and $100 \mathrm{MPa}$ per square meter, depending on the annealing temperature [2]. Its excellent strength, fatigue resistance and toughness, as well as the ability to maintain its strength at a temperature of above $350^{\circ} \mathrm{C}[5,6]$, made Ti-64 the most produced and used alloy among Titanium alloys. Over $80 \%$ of the Ti-64 produced in USA and Europe is utilised in the aerospace industry because of its low density and excellent balance of mechanical properties[7]. However, several other titanium alloys have been developed for the aerospace industry such as Ti-6Al-2Sn-2Zr-2Mo-2Cr which has an ultimate strength of $1100 \mathrm{MPa}$ and a toughness of $100 \mathrm{MPa}$ per meter square; Ti-10V-2Fe-3Al with an ultimate strength of $1240 \mathrm{MPa}$ and a typical toughness of $55 \mathrm{MPa}$ per square meter [2]; or Ti-5Al-4V-0.7Mo-0.5Fe (Ti54M) with an ultimate strength of $925 \mathrm{MPa}$ and higher machinability [8]. These and other titanium alloys are used to manufacture frames, engine parts, hydraulic pipes, landing gear parts, track beams, exhausts, tail cones and airplane ducts [8]. Currently, most Titanium alloys developed for airframe are focused on cost reduction, mainly at the manufacturing stage, with relatively limited savings gone towards performance improvements [2].

Alongside Titanium alloys, Aluminium alloys are also used in the aerospace industry, more specifically, in commercial aircraft because of their low density. The primary structural aluminium alloys used in aerospace have been the copper-containing (2XXX) and the zinccontaining (7XXX) alloys [2]. These alloys have been modified to improve their strength, toughness and corrosion resistance, resulting in newer alloys such as 7150 and 7055 . These improvements were attained by decreasing the levels of impurities, such as iron and silicon, which reduces the volume fraction of coarse second-phase. These secondary phases are frequently the nucleation sites for fatigue damage and fracture [2]. Among Aluminium alloys, Aluminium-Lithium (Al-Li) alloys have the most attractive properties in terms of density and stiffness because of the addition of Lithium [9]. The density of an Aluminium alloy is reduced by $3 \%$ and the stiffness is increased by $6 \%$ with every $1 \%$ addition of Lithium [10]. However, high addition of Lithium increases the anisotropy of the alloy, therefore, the $3^{\text {rd }}$ generation of Al-Li alloys have a reduced amount of Lithium content compared to the $2^{\text {nd }}$ generation of Al-Li alloys [10]. AA2099 is a $3^{\text {rd }}$ generation Al-Li alloy which has good mechanical properties and corrosion resistance [11] and is used frequently in modern commercial aircraft structural components [12]. Its maximum service temperature is below $180^{\circ} \mathrm{C}$, above which it begins to lose strength significantly [13], however, it performs very well in cryogenic temperatures. As with all Aluminium alloys, AA2099 does not experience ductile-to-brittle transformation. The favourable 
mechanical properties united with low density make the AA2099 alloy a suitable candidate for applications in aircrafts. Yet, its applications are restricted to airframe structures since this alloy does not possess the amount of fatigue and creep resistance required in the aeroengines components. On the other hand, AA2099 is suitable for lower and upper wing stringers, fuselage stringers, floor beams, seat rails and internal structures of fuselage applications where high strength, toughness and lower weight is required [1,14]. For example, in the Airbus A380, the conventional Al-Cu alloys 2026 and 2027 were replaced by the 3rd generation Al-Li alloys including the 2099 alloy for the lower wing skin which lead to weight savings of $740 \mathrm{~kg}$ because of the lower density and higher strength of these alloys [15].

A brief comparison of Ti-64 and AA2099 extrusions is given in Table 1. The mechanical properties of both of these alloys can be altered through various heat treatment techniques as both are heat treatable $[2,16]$.

Table 1 Properties of Ti-6Al-4V and AA2099 [11], [17]-[24]

\begin{tabular}{c|cc}
\multicolumn{1}{c}{ Properties } & Ti-6Al-4V & AA2099 \\
\hline Composition & Al: $6 \%, \mathrm{~V}: 4 \%, \mathrm{Fe}:<0.3 \%, \mathrm{O}:$ & Li: $1.8 \%, \mathrm{Cu}: 2.7 \%, \mathrm{Mg}:$ \\
& $<0.3 \%, \mathrm{Ti}:$ Remainder & $0.3 \%, \mathrm{Zr}: 0.09 \%, \mathrm{Mn}:$ \\
& & $0.3 \%, \mathrm{Zn}: 0.7 \%, \mathrm{Al}:$ \\
Stiffness & & Remainder \\
Yield Strength & $114 \mathrm{GPa}$ & $78 \mathrm{GPa}$ \\
Tensile Strength & $930 \mathrm{MPa}$ & $505 \mathrm{MPa}$ \\
Fracture Toughness & $1070 \mathrm{MPa}$ & $595 \mathrm{MPa}$ \\
Density & $65 \mathrm{MPa} \sqrt{\mathrm{m}}$ & $30 \mathrm{MPa} \sqrt{\mathrm{m}}$ \\
Thermal expansion coefficient & $4420 \mathrm{~kg} / \mathrm{m}^{3}$ & $2630 \mathrm{~kg} / \mathrm{m}^{3}$ \\
& $9.2 \times 10^{-6} / \mathrm{K}$ & $28 \times 10^{-6} / \mathrm{K}$
\end{tabular}

A pylon is a structural component within the frame of the aircraft [25]. The pylons in commercial aircrafts such as the Airbus A380, A330 and A350 are currently made with Ti-64 [26-29]. The aim of this study was to determine if pylons of commercial aircraft can potentially be substituted using AA2099. The reason for using AA2099 was that it has lower density than Ti64 which can potentially offer weight savings if used as a replacement of Ti-64. In the current available literature, there have not been studies which substitute the material of the pylon.

\section{MATERIALS AND METHODS}

A pylon is a critical aircraft component that connects the engine to the aircraft. Engines can be attached to an aircraft through various configurations. It can be attached on the sides of the fuselage, above the wing or below the wing. For commercial aircraft, however, engines are mostly attached below the wings to reduce the interference between the wing and engine, improve the stability of the engine, ease of access to the engine during maintenance and ensure less noise is transferred to the cabin [30]. Nonetheless, in all cases, engines are attached to the aircraft through pylons. The pylon is connected to the engine through engine mounts which are 
usually made with high strength steels [31]. The pylon is also enclosed in a fairing to give it an aerodynamic shape.

In this study only the main structural component of the pylon, also known as the pylon box, was analysed. The engine attachment configuration used for this study was below the wing attachment. The engine used was the Rolls-Royce Trent 900 which has a mass of around $6246 \mathrm{~kg}$ and can produce a maximum thrust of $374 \mathrm{kN}$ [32]. The shape of the pylon used was that of the Airbus A320. The cross-sectional view of A320's pylon is shown in Figure 1.

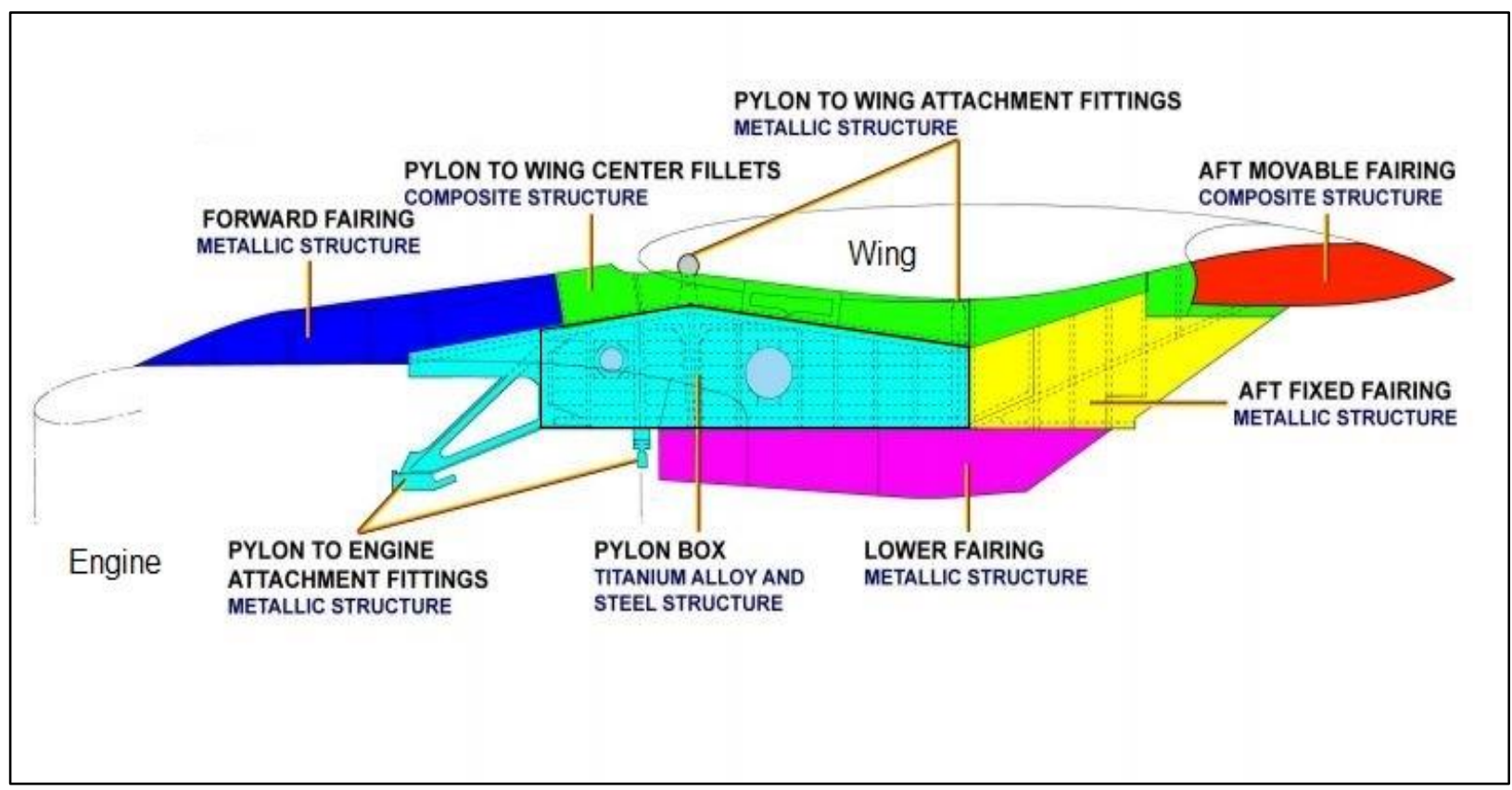

Fig. 1. Cross-sectional view of Airbus A320's pylon [29]

In order to determine if the material of the pylon can be changed from Ti-64 to AA2099, the pylon was analysed in terms of the types of loads acting on it, its maximum and minimum temperatures, potential corrosion factors, manufacturability and recyclability. Next, the behaviour of both Ti-64 and AA2099 under the conditions which the pylon can experience was examined. For the temperature, corrosion, manufacturability and recyclability constraints, theoretical analysis was conducted whereas for the loads acting on the pylon, finite element analysis (FEA) was conducted to determine how both materials will perform, as discussed below.

\section{Temperature}

A pylon is connected to the engine mounts and the wing mounts. The temperature of the engine mounts can reach very high levels due to their proximity to the engine. However, the turbofan engines' bypass cool air flows over the engine mounts which keeps the casing of the engine cool. When the plane is stationary on the ground, the temperature of the engine casing can reach as high as $400^{\circ} \mathrm{C}$ but at a high altitude, this can become as low as $-40^{\circ} \mathrm{C}$ due to the low temperature in the air $[33,34]$. An incident investigation report of the Airbus A330 showed that the pylon temperature can reach a maximum of around $80^{\circ} \mathrm{C}$ when the engine starts and the temperature of the pylon reduces at a rate of $1 \%$ min during the climb of an aircraft [35]. 


\section{Corrosion}

Although the pylon is enclosed in the fairing, it encounters incoming bypass air from the turbofan engine. Environmental factors such as rain and polluted air can affect the rate of corrosion of the pylon. With the presence of an electrolyte such as rainwater between the contact surface of two materials, galvanic corrosion can occur if there is a significant difference between the electrode potentials of the materials [36].

\section{Manufacturability}

The main structural component of the pylon is a truss made up of beams. These beams can be made through casting and extrusion processes. The beams need to be made from a material that is ideally weldable since a number of beams must be welded together to form the frame of the pylon. The beams can also be joined by other processes such as mechanical fastening. The material utilised for the pylon should also be machinable since extruded or casted parts may need to be machined further for the specific application as required.

\section{Recyclability}

Many industries, including the aerospace industry, are attempting to use recyclable materials as these can be reused rather than producing the material from ore which requires more energy [37]. Fundamentally, using recycled materials would also have a less harmful impact on the environment. Therefore, as with any other structural component, the recyclability of the pylon box is also important. In case the components of a pylon are replaced, the old parts can be recycled into raw material if it is made with recyclable material.

\section{Loads}

The pylon must be able to withstand the forces produced by the engine weight and thrust. A pylon is responsible for transferring the engine thrust and weight to the wing of an aircraft. The loads due to the engine thrust and weight alter in different scenarios. Three critical scenarios were chosen for this study which were aircraft take-off, hard landing of an aircraft, and an aircraft taking a sharp turn in flight with a high banking angle. During take-off, the engine is at full thrust and the plane is accelerating forwards and upwards. The maximum load factor occurring at takeoff is around $1.4 \mathrm{~g}$ [38], i.e., the acceleration of gravity multiplied by a factor of 1.4. During hard landing, the maximum threshold load factor for the Airbus A320 is around $2.6 \mathrm{~g}$ [39], while the engine is at zero thrust since the aircraft is landing. In sharp turning, the maximum allowed banking angle of a commercial aircraft is $75^{\circ}$, which produces a load factor of $4.4 \mathrm{~g}$ due to the combination of the centrifugal forces acting on the engine and the weight of the engine [40]. The engine is at full thrust in the sharp turning scenario. FEA was used for the simulation of loads acting on the pylon. Figure 2 shows a simplistic 2-Dimensional representation of how the forces were applied in the simulations. 


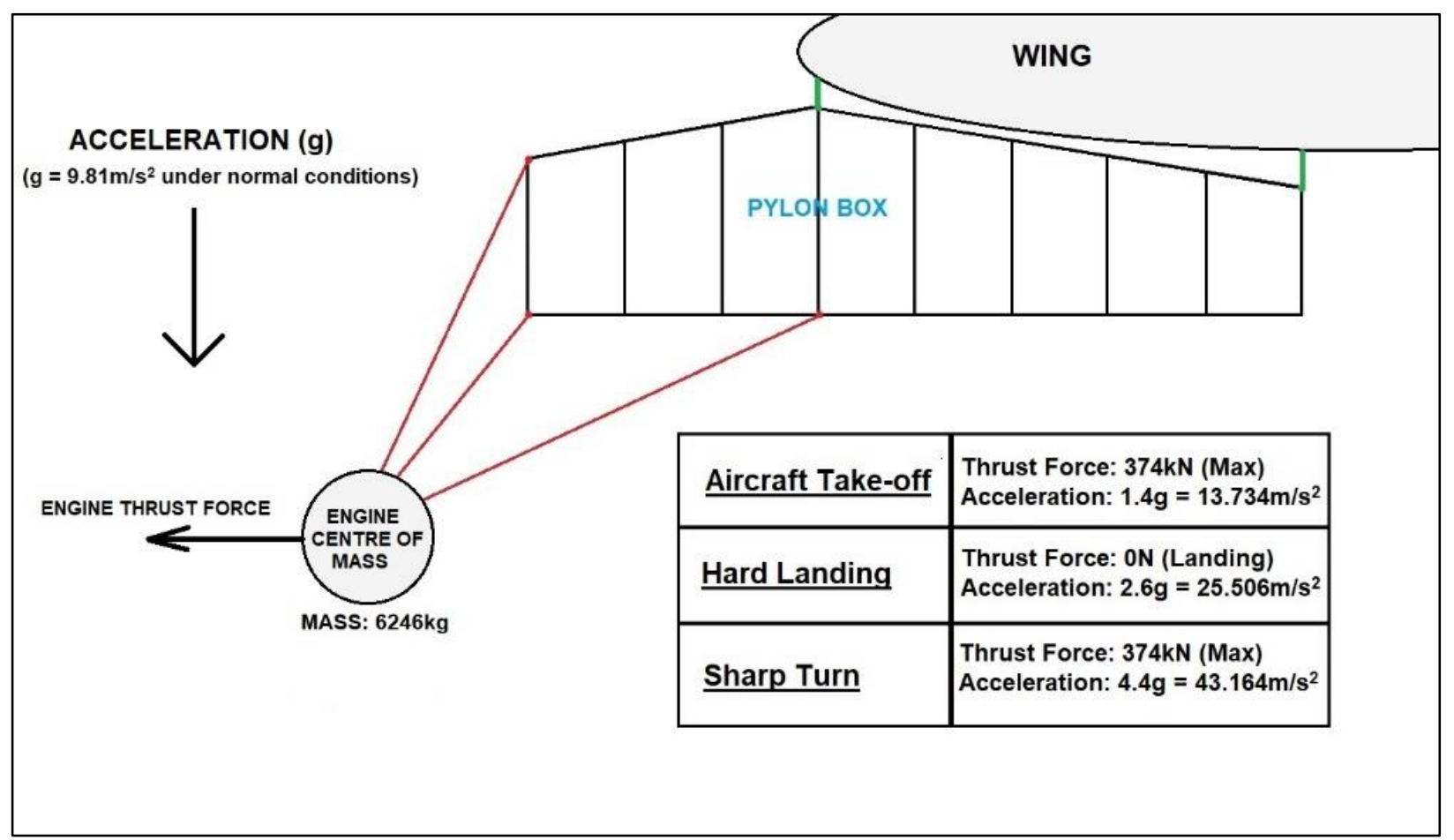

Fig. 2. A 2-D representation of the FEA model

\section{Fatigue}

A wing is essentially a beam that transmits the entire applied air load to the central attachment to the fuselage. As the pylon transfers the engine thrust and weight to the wing of an aircraft, the same way, the wing transfer to the pylon the forces it experiments. The pylon takes torsion loads as the wing tries to twist during flight. Additionally, the lower skin-stringer of the wing, usually in contact with pylon, is primarily in tension during flight and in compression during taxiing [41]. This alternating load made fatigue resistance within the material of most importance.

R. A. Antunes [42] reported that the fatigue limit and yield strength of metallic alloys are directly correlated. The difficulty of obtaining these data lie on the fact that the alloy microstructures and its thermomechanical processing history can lead to different fatigue behaviours for the same particular alloy [43]. Moreover, the fatigue limit is also affected by the type of crack initiation. Microstructures that favour subsurface crack initiation provide higher fatigue limit than those where surface crack initiation dominates [42]. Therefore, due to the lack of fatigue data for the present work, it was decided to assume the yield strength as an indicator for fatigue resistance. Nonetheless, one should keep in mind that this approach is an approximation and does not remove the need for actual fatigue data in the future. 


\section{FINITE ELEMENT ANALYSIS}

The line body geometry was made in the ANSYS Design Modeler using the dimensions given in Figure 3. Rectangular beams were assigned to each line as frozen bodies so that the dimensions of the cross-section of each individual beam could be changed for optimisation. Initially, a $50 \mathrm{~mm}$ by $50 \mathrm{~mm}$ cross-section was used for the beams. The following values were chosen as parameters for the geometry optimisation tool in ANSYS:

1. The dimensions of the cross-section of each beam.

2. The mass of the complete geometry.

3. The maximum stress in the take-off, hard landing and sharp turning scenarios.

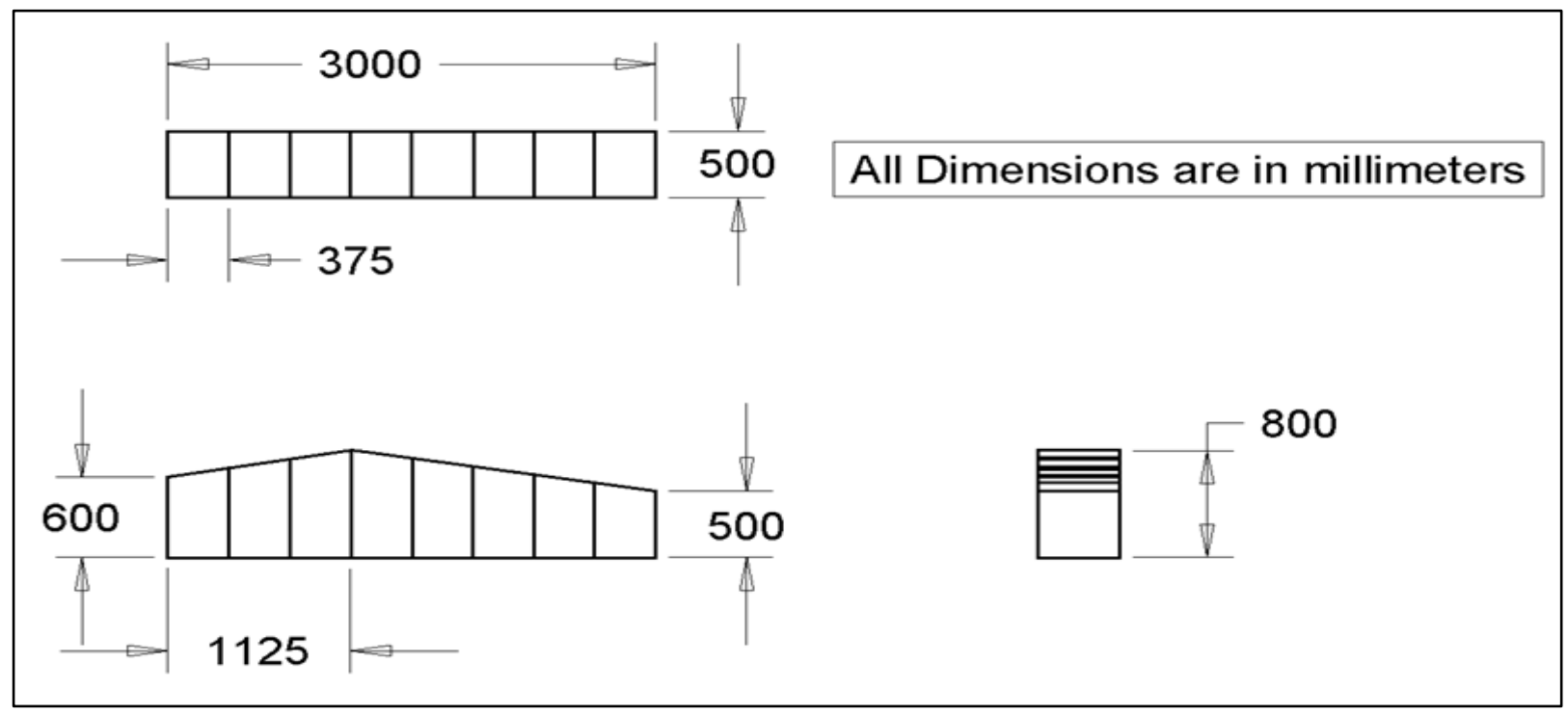

Fig. 3. 2-D drawings showing the dimensions of the pylon line body

Figure 4 shows the constraints applied on the pylon with $50 \mathrm{~mm}$ by $50 \mathrm{~mm}$ beams. The temperature of the whole structure in the simulation was taken as $80^{\circ} \mathrm{C}$. The point mass shown in Figure 4 represents the engine centre of mass. The red lines connecting the point mass and the pylon show how the engine was connected to the pylon for this analysis. The vertical red lines in Figure 4 show the wing attachment points which were fully fixed. A remote force was applied on the point mass representing the engine thrust. The reason for using the remote displacement is that the behaviour of the support can be set as deformable support which does not produce structural singularities in the location of the supports unlike using simple fixed supports. A point mass was taken at a point where the engine's centre of mass would be and it was attached to the points where engine mounts are connected to the pylon box which are represented by the red nodes in Figure 4.

A remote force, representing the thrust of the engine, was also applied at the same location as the point mass using the same attachment points. The value of the remote force was taken as $374 \mathrm{kN}$ in the take-off and sharp turning scenarios which is the maximum thrust that can be produced by the Rolls-Royce Trent 900 engine [32]. 


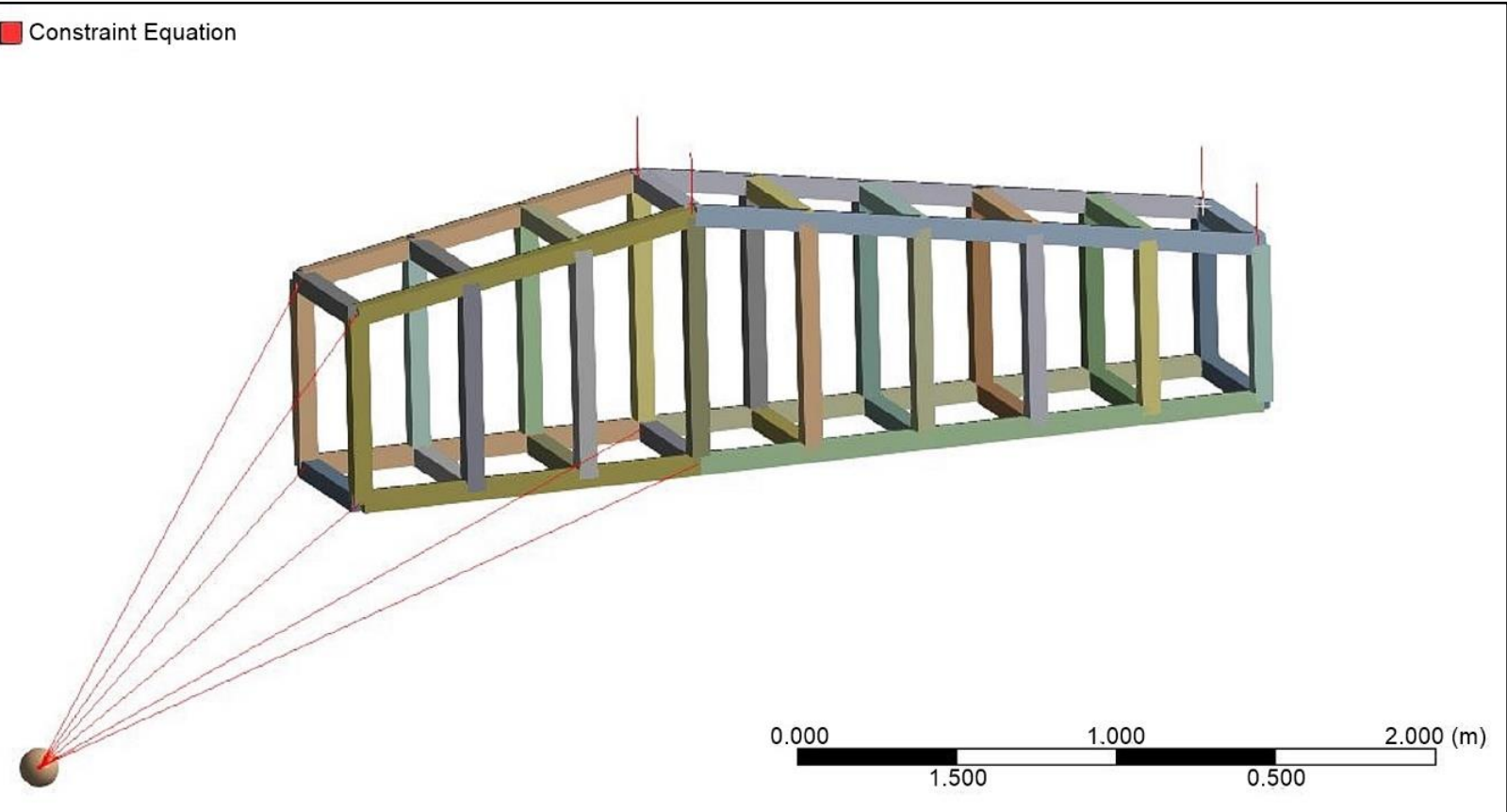

Fig. 4. Beam model showing the constraints applied on the pylon

The thrust was taken as zero in the hard landing scenario since the aircraft is landing as no thrust is required. The acceleration due to gravity was applied using load factors depending upon each scenario. The mesh of the model was created using uniform hexagonal elements with sizing of $5 \mathrm{~mm}$. The meshed geometry showing the solid beams model is shown in Figure 5.

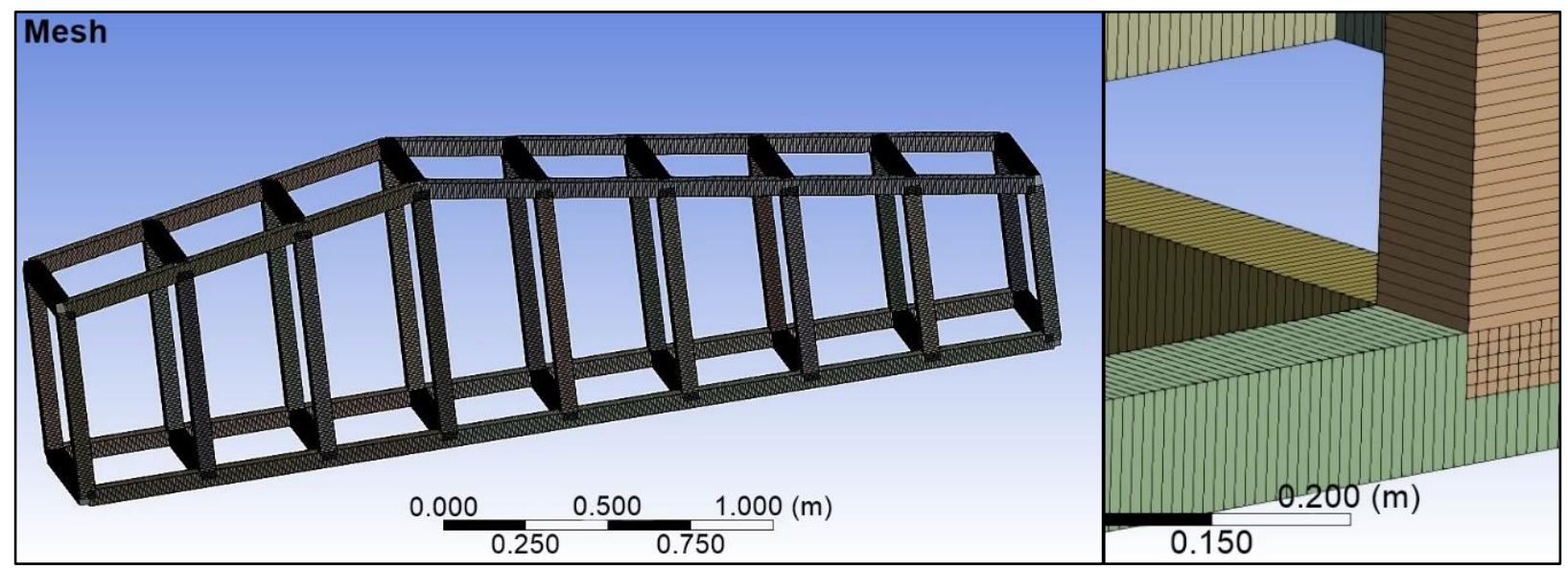

Fig. 5. Mesh of the model, showing a detailed view of the meshing on the right-hand side

Firstly, the material assigned to the geometry was Ti-64 and the loads were applied in three structural components representing the three loading scenarios. The Response Surface Optimisation tool in ANSYS was used with the objective of minimising both the mass of the geometry and the cross-sectional area of the beams, while keeping the stress under 1.5 factor of safety limit of the material using the ultimate tensile strength criteria. The same method was 
applied for the material of the pylon being AA2099. The ultimate tensile strength divided by a factor of safety of 1.5 for Ti-64 is $713.33 \mathrm{MPa}$ whereas for AA2099, it is 396.66 MPa. The 1.5 factor of safety based on the ultimate tensile strength is commonly used for aircraft structures [44].

\section{RESULTS}

\section{Temperature}

Based on the temperature range required of the pylon, both Ti-64 and AA2099 are suitable for it as a material. Ti-64's service temperature is well above the maximum temperature and it is also suitable for the lowest temperature of the pylon. Ti-64 experiences ductile-to-brittle transition at low temperatures, but the transition temperature is well below the pylon's minimum temperature. On the other hand, AA2099 has much lower service temperature compared to Ti-64, i.e., $180^{\circ} \mathrm{C}$, but this is still higher than the maximum temperature of the pylon. Since all Aluminium alloys perform exceptionally at cryogenic temperatures, the lowest temperature of the pylon would not affect the performance of AA2099.

\section{Corrosion}

Both Titanium and Aluminium alloys are effective at resisting environmental corrosion because of the formation of an oxide layer when exposed to air which acts as a protective layer $[45,46]$. However, Al-Li alloys do not possess the corrosion resistant characteristic like other Aluminium alloys. Still, AA2099 has very good corrosion resistance compared to other Al-Li alloys. So, in terms of environmental corrosion, both materials can be used for the pylon, with Ti64 being more resistant to corrosion. In terms of galvanic corrosion, Ti-64 is resistant due to its noble electrode potential [36]. However, Aluminium alloys, including AA2099, are highly prone to galvanic corrosion because of their negative electrode potential [36]. The pylon is connected to engine mounts, wing mounts and the fairings. The mounts are usually made with high strength steels or Nickel-based super alloys. If Aluminium is in contact with steel, Nickel alloys or Carbon composites, galvanic corrosion will occur in the Aluminium component because of difference in electrode potential. Moreover, the use of Carbon composites is increasing in aircraft because of their high strength-to-weight ratios and Aluminium alloys experience a high degree of galvanic corrosion when in contact with Carbon composites. This is due to the high difference between the electrode potential of Aluminium and Carbon [36]. However, this issue can be addressed with appropriate coating mechanisms. In contrast, Ti-64 does not experience galvanic corrosion when in contact with Carbon composites because there is no significant difference in the electrode potential of Titanium and Carbon.

\section{Manufacturability}

Aluminium has good formability but Al-Li alloys, including AA2099, have poor formability among Aluminium alloys [47]. However, AA2099 is available in extrusion forms commercially which is suitable for the pylon beams [11]. In contrast, Ti-64 can be forged or superplastically

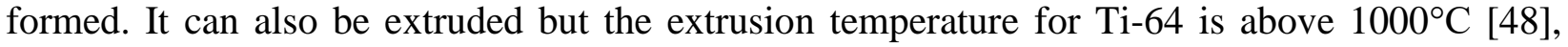


while that of AA2099 is around $500^{\circ} \mathrm{C}$ [49] which makes the extrusion of AA2099 more costeffective. In terms of machineability, both AA2099 and Ti-64 are machinable. However, the machining of Ti-64 requires more energy due to its hard nature and low thermal conductivity compared to the soft nature and high thermal conductivity of AA2099. Generally, the machining costs of Titanium alloys is about 10 times that of Aluminium alloys [50].

Aluminium alloys are generally very low cost, but Al-Li alloys are the most expensive among Aluminium alloys because of Lithium's high reactivity. Nevertheless, they still cost less overall than Titanium alloys [50]. As for the alloys under consideration, the cost of Ti-64 is about $£ 16.27 / \mathrm{kg}$ [51], while the cost of AA2099 extrusion is $£ 5.86 / \mathrm{kg}$ (courtesy of Aalco, 2020).

\section{Recyclability}

The recyclability data about AA2099 specifically is not well documented, however extensive research has been conducted on the recyclability of Aluminium alloys which are $100 \%$ recyclable [52].The recyclability of Aluminium alloys is far more economical than that of Titanium alloys. The energy required for recycling the scrap of Aluminium is about $5 \%$ of the energy required to produce it from ore, which implies $95 \%$ less greenhouse gases compared to extraction from ore [53]. With the use of modern technology, Aluminium alloys can be recast repeatedly without affecting the quality of the alloy [52]. The low melting point of Aluminium and its alloys makes them easier to melt and able to be extruded into different shapes. The recyclability of Aluminium and its alloys is the most out of any metals; around $60 \%$ of Aluminium products are recycled at the end of their life cycle but this number is further improving [54].

On the contrary, Titanium alloys are also $100 \%$ recyclable but they are recycled to a far less extent commercially [55]. Titanium and Titanium alloy scrap is recycled because of the high value of the metal but the processes available are not as cost-effective; therefore, only $30 \%$ of Titanium chips are used to produce new ingots [56]. One of the challenges of recycling Titanium alloys is the heat resistant property of Titanium which makes it difficult to melt and special melting devices are required for it. However, a new French company called 'EcoTitanium' is solving the Titanium recycling issue by use of advanced furnaces and technologies [57].

\section{FEA Results}

In order to obtain the optimised geometries for both Ti-64 and AA2099, the Response Surface Optimisation tool in ANSYS was used. The objectives of the optimisation were to minimize the mass of the whole geometry and maintain the maximum stress lower than the 1.5 factor of safety limit. This was done for both Ti-64 and AA2099 geometries. The total deformation and maximum stress results for both optimised geometries were produced. The Ti64 optimised geometry had a mass of $203.13 \mathrm{~kg}$ and a total volume of $0.045546 \mathrm{~m}^{3}$, while those of the AA2099 optimised geometry were $180.82 \mathrm{~kg}$ and $0.068753 \mathrm{~m}^{3}$. The maximum stress for both optimised geometries in the take-off scenario is given in Figure 6 and 7. 


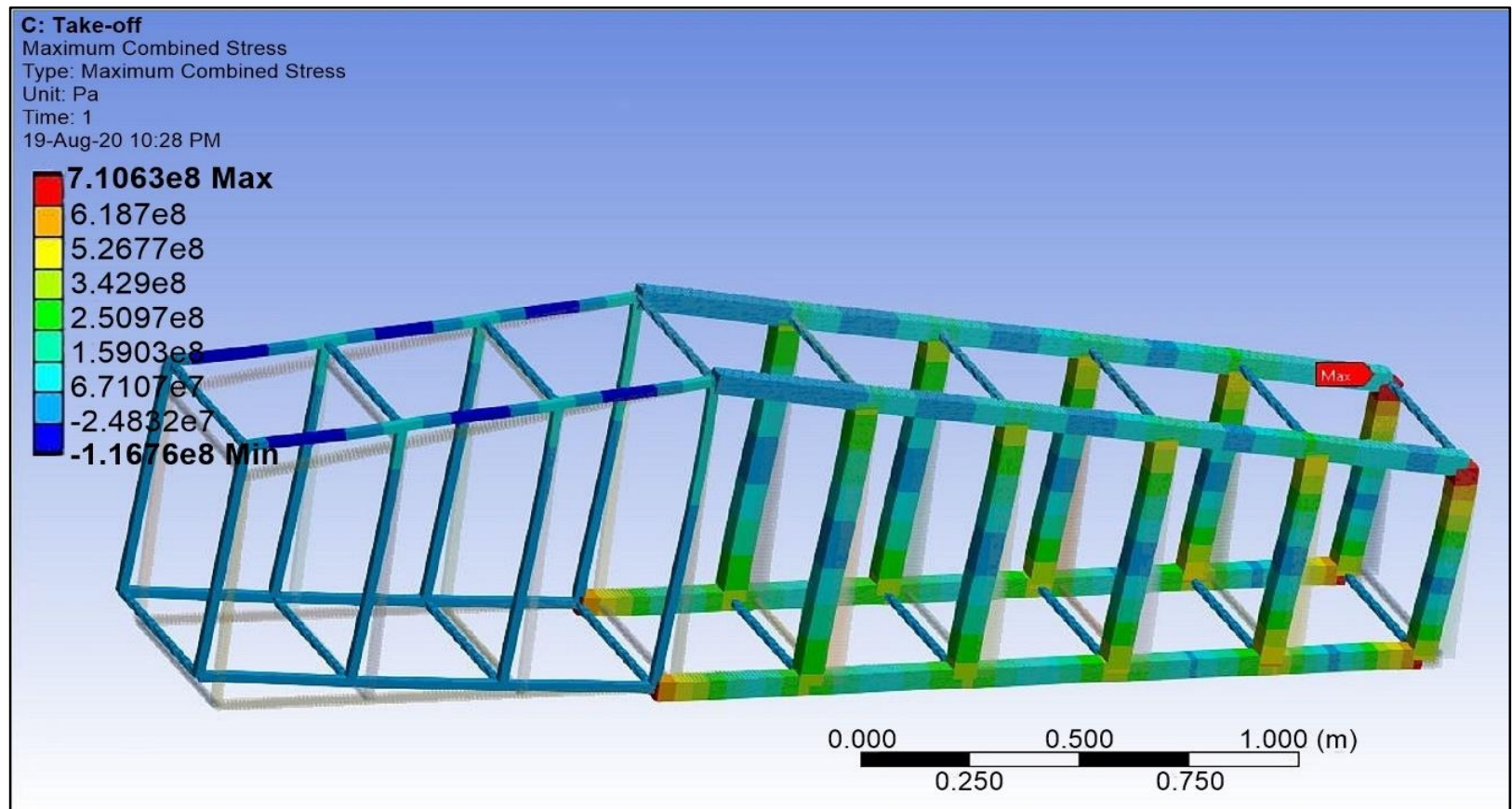

Fig. 6. Maximum stress in the Ti-64 optimized geometry in the Take-off scenario

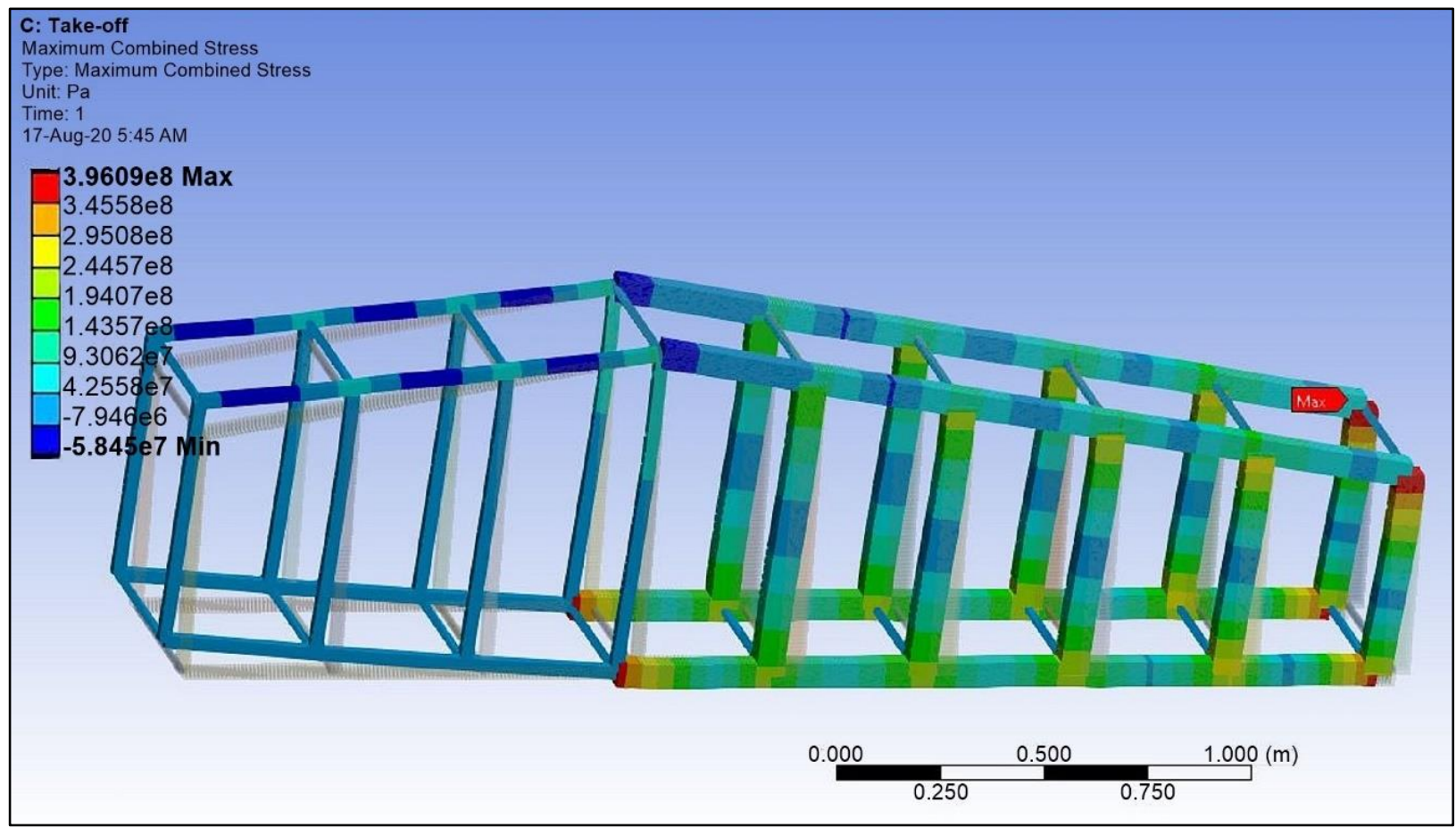

Fig. 7. Maximum stress in the AA2099 optimized geometry in the Take-off scenario

The rear beams of the pylon were under the most stress in the take-off scenario and the pylon had deflected upwards, which is because of the engine thrust making a moment since the engine 
is located below the pylon. The weight of the engine with the $1.4 \mathrm{~g}$ load factor did not have a significant effect on the total resultant force because the magnitude of the thrust force is very high compared to the weight. Similarly, in the hard landing scenario, the pylon was deflected downwards because the engine thrust was taken as zero and the weight of the engine was multiplied by a factor of 2.6. The highly stressed beams in the hard landing scenario were the front and the top beams. In the sharp turning scenario however, the engine is at full thrust, but the weight of the engine was multiplied by a factor of 4.4 which changed the direction of the resultant force significantly. Due to this, the maximum stress and deformations were the lowest in the sharp turning scenario even though the magnitude of the resultant force was highest in this scenario. Figure 8 shows the values of total deformation and maximum stress in the optimised geometries of both Ti-64 and AA2099 pylons.

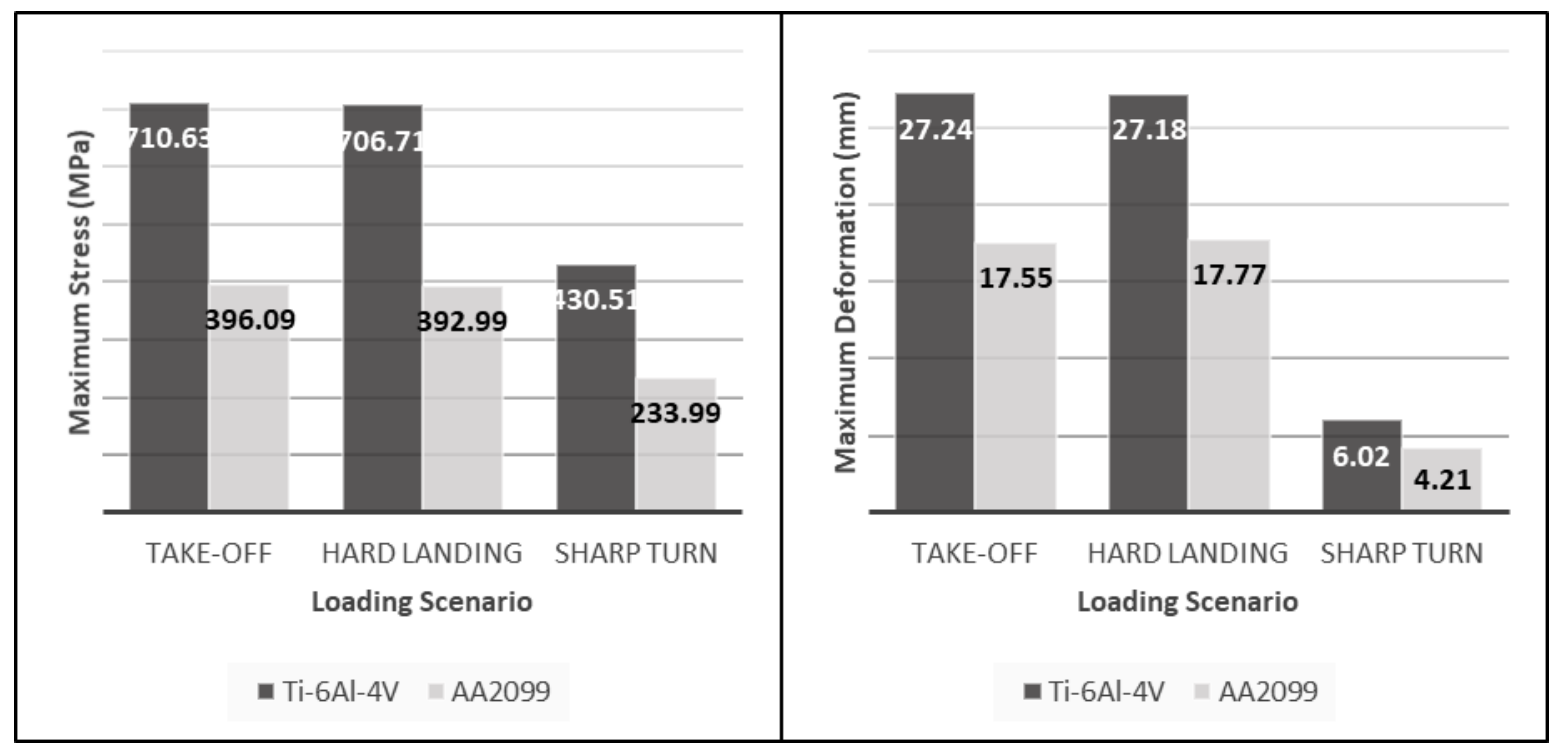

Fig. 8. (a) The maximum stresses comparison of Ti-64 and AA2099 pylons against the three loading scenarios, and (b) total deformation comparison of the two materials used for the pylon in the three loading scenarios

\section{Fatigue}

Fatigue behaviour of aluminium alloys is critical since more than $40 \%$ of damages repaired during aircraft maintenance initiates from metal fatigue [58]. Data about AA2099, in comparison with the first and second generation of aluminium-lithium alloys, include improved strength, modulus, corrosion resistance, and fatigue and damage tolerance. Mainly due to the aluminiumcopper-lithium system with lower lithium contents, targeting strength improvements with modest reductions in density. Additionally, by incorporating minor levels of elements, such as silver and zinc, the strength and corrosion resistance increase. AA2099 shows also improvements in microstructure control through thermomechanical processing and heat treatment that can tailor the fatigue resistance characteristics of the alloy [2].

Titanium alloys are known to undergo fatigue damage in typical aircraft operation environments [59]. Cast Ti alloys tend to have large grains (in the order of several $\mathrm{mm}$ ). This large grain size limits its fatigue resistance as the cracks have an easier road for growth. This problem can be addressed in Ti-64 via several thermo-mechanical steps to reduce the grain size. 
This, in turn, makes the finished components of Ti-64 considerably expensive [60]. Moreover, the fatigue life behaviour of Ti-64 depends on its $\alpha+\beta$ microstructure volumes which varies depending on the heat treatments carried out on the alloy. Higher levels of $\beta$ hinders the fatigue resistance of the material while a higher volume of $\alpha$ increase this limit [61].

For AA2099 alloy to replace Ti-64 in aircraft structures, its mechanical behaviour and damage tolerance capabilities should be equal or superior to those of Ti-64. Using the yield strength approach, Ti-64 with a yield strength $400 \mathrm{MPa}$ above AA2099 could be considered to have a higher fatigue resistance, however this cannot be investigated in this work as the total processing history for both alloys needs to be known [43].

\section{DISCUSSION}

The results obtained from the ANSYS simulation showed that under the same constraints and the same factor of safety, the AA2099 geometry offered a weight reduction of about $11 \%$ compared to Ti-64. However, it also increased the total volume of material used by $51 \%$. The reason being, AA2099 is a very lightweight material but its strength is nearly half of Ti-64's. The deformations in the AA2099 model are also around 30\% less than the Ti-64 pylon in all three loading scenarios. In terms of manufacturability, the truss of pylon can be made with both materials. However, machining AA2099 is more cost-effective compared to Ti-64. In terms of the cost of the material based on this analysis, the AA2099 pylon would cost less than one third of the Ti-64 pylon, that is without the considering the machining costs. The recyclability of AA2099 would also be easier and more cost-efficient because of its low melting point compared to Ti-64. In terms of galvanic corrosion however, AA2099 as all Aluminium alloys would be more prone to galvanic corrosion since the pylon is in contact with different materials.

In the FEA simulation, the pylon attachment to the wing was taken to be fully fixed whereas in reality, the pylon is attached to wing and wing also has a certain stiffness. The effects of crosswinds and wing vibrations due to turbulence were not analysed in this study. Furthermore, the weight used for the engine was that of the bare engine. The weight of the nacelle, the engine mounts and the fuel inside the engine were not considered in this study. However, since this was a comparative study and conditions were kept the same for both materials, these can be overlooked. Furthermore, the effect of the aerodynamic drag on the engine nacelle and pylon fairing was not considered. However, the direction of the drag on these would be opposite to the engine thrust, so not considering these provided a more conservative design. Future work in this area should include the wing stiffness in the analysis, which will give a more realistic design. To tackle galvanic corrosion, a coating can be applied on the pylon if it is made with AA2099. The effectiveness and the cost of the coating should be analysed.

\section{CONCLUSIONS}

Based on the analysis conducted, the following conclusions can be made:

1. Replacing Ti-64 with AA2099 for the manufacture of aircraft components offers weight savings.

2. AA2099 is an ideal material for components in the aircraft which have maximum temperatures below its service temperature. 
3. Galvanic corrosion is one of the main disadvantages of Aluminium alloys in aircraft structures which are in contact with other materials with differences in electrode potential and are exposed to the environment.

4. The increased use of Carbon composites in aircraft can hinder the use of Aluminium alloys since significant galvanic corrosion occurs in Aluminium when it in contact with Carbon composites.

AA2099 is a relatively new alloy with good mechanical properties and very low density thus, it can find numerous applications in aircraft components. In the current literature available, there has not been many studies which focused on replacing Ti-64 with newer Al-Li alloys for aircraft components and specifically the aircraft pylons. However, the results based on this study show AA2099 as a suitable replacement for Ti-64 in the aircraft pylon based on the material requirements.

\section{REFERENCES}

1. Prasad N.E., Wanhill R.J.H. Aerospace materials and material technologies. Vol. 3. Singapore: Springer, 2017.

2. Boyer R.R. An overview on the use of titanium in the aerospace industry. Materials Science and Engineering: A, 213(1-2) (1996) 103-114.

3. Bell T. Titanium properties and characteristics. ThoughtCo. (2019).

4. Sankaran K.K., Mishra R.S. Titanium alloys. In: Metallurgy and design of alloys with hierarchical microstructures. (2017) 177-288.

5. Donachie M.J. Introduction to selection of titanium alloys. In: Titanium - a technical guide. Ohio: ASM International. (2000) 5-11.

6. Tolvanen S. Microstructure and mechanical properties of Ti-6Al-4V welds produced with different processes. Chalmers University of Technology, Gotthenburg, Sweden. (2016).

7. Singh P, Pungotra H, Kalsi N.S. On the characteristics of titanium alloys for the aircraft applications. Materials Today, (2017) 8971-8982.

8. Gomez-Gallegos A, Mandal P, Gonzalez D, Zuelli N, Blackwell P. Studies on titanium alloys for aerospace application. Defect and Diffusion Forum, 385 (2018) 419-423.

9. Rioja R.J. Fabrication methods to manufacture isotropic Al-Li alloys and products for space and aerospace applications. Materials Science and Engineering: A, 257(1) (1998) 100-107.

10. Rioja R.J, Liu J. The evolution of Al-Li base products for aerospace and space applications. Metallurgical and Materials Transactions A, 43(9) (2012) 3325-3337.

11. Alloy 2099-T83 and 2099-T8E67 extrusions. Datasheet. Alcoa Inc, Bettendorf, Iowa, USA (2005).

12. Dong H, Guo F, Huang W, Yang X, Zhu X, Li H, Jiang L. Shear banding behavior of AA2099 AlLi alloy in asymmetrical rolling and its effect on recrystallization in subsequent annealing. Materials Characterization, 177 (2021) 111155.

13. Balducci E, Ceschini L, Messieri S. High temperature tensile tests of the lightweight 2099 and 2055 Al-Cu-Li alloy: A comparison. JOM, 70(11) (2018) 2716-25.

14. Dorin T, Vahid A, Lamb J. Aluminium Lithium Alloys. In: Fundamentals of Aluminium Metallurgy Woodhead Publishing, (2018) 387-438. 
15. Busson G, Preist J. A380 capability and profitability enhancements. FAST A380 Special Edition (2016).

16. Aluminium Alloy Specifications. Datasheet. Aalco Metals Limited, Wednesbury, Great Britain, (2020).

17. Boyer R, Welsch G, Collings E.W. Materials Properties Handbook - Titanium alloys. ASM International, (1994).

18. Corrosion resistance of titanium. Titanium Metals Corporation. Denver, Colorado, (1997).

19. Davis JR. Aluminum and Aluminum Alloys. Light Met Alloy. ASM International, (2001) 351-416.

20. Titanium Alloys - Ti6Al4V Grade 5. U.S. Titanium Industry Inc. - AZO Materials, (2002).

21. Morrissey R.J, Nicholas T. Fatigue strength of Ti-6Al-4V at very long lives. International Journal of Fatigue, 27(10-12) (2005) 1608-12.

22. Ti-6Al-4V (Grade 5). Datasheet, Biggleswade, Great Britain (2018).

23. Titanium Ti-6Al-4V. Datasheet, Newbury, Great Britain (2020).

24. Yang R, Yang J, Xie K, Liu Z, Zhang G. Investigation of micro-yield strength and coefficient of thermal expansion of Al-Cu-Mg-Li-Sc-Ag alloys with various contents of Li. Journal of Materials Research, 34(15) (2019) 2714-2726.

25. Thomas R.H, Czech M.J, Elmiligui A.A. Active Aircraft Pylon Noise Control System. US Patent LAR-TOPS-179.

26. Structural blind fasteners. Flight Airworth Support Technology, (27) (2019) 26-9.

27. Ferrer G, Chamfroy C, Dupouy. SS. A350 XWB composite repairs. Flight Airworth Support Technology, (2016) 32.

28. Pora J. Advanced materials and technologies for A380 structure. Flight Airworth Support Technology, (2003) 32.

29. A320 family (CFM56) familiarization course. Islamabad, Pakistan (2018).

30. Kämpf $P$. Why not mount airliner jet engines above the wings? https://aviation.stackexchange.com/questions/9680/why-not-mount-airliner-jet-engines-above-thewings.

31. Heid T. The ABC's of Engine Mount Inspection \& Repair. Aviation Pros, (2000).

32. Trent 900. Rolls-Royce.

33. Morris H. Why planes fly at 35,000 feet: The reason for high altitude flights. Traveller, (2017).

34. Acron Welding. Aircraft engine mounts- here's what you need to know. Acron Welding, (2020).

35. Investigation report A330 jetliners' engine bleed air system failures: Serious Incidents on 11 and 22 December 2010. Helsinki, Finland (2012).

36. Mitchell J. The galvanic series - the essential guide. Engineering Clicks, (2017).

37. Aircraft \& Composite Recycling. Boeing. environmental Technotes, 12(1) (2007) 1-4.

38. Meilak J. How G-Force works. MiGFlug, (2018).

39. Dubois P. Towards an efficient FDA Programme. Miami, USA (2016).

40. Aviation Security Service. Maximum rate turns. Civil Aviation Authority New Zealand, (2020). 
41. Chen B, Li C.H, He S.C, Li X.L, Lu C. Corrosion behavior of 2099 Al-Li alloy in NaCl aqueous solution. Journal of Materials Research, 29(12) (2014) 1344-1353.

42. Antunes R.A, de Oliveiraa M.C.L, Salvador C.A.F. Materials selection of optimized titanium alloys for aircraft applications. Materials Research, 21(2) (2017).

43. Bylya O, Gomez-Gallegos A, Stefani N, Blackwell P. Al-Li alloys - the analysis of material behaviour during industrial hot forging. Procedia Engineering, 207 (2017) 7-12.

44. Modlin C.T, Zipay J.J. The $1.5 \& 1.4$ ultimate factors of safety for aircraft \& spacecraft - history, definition and applications. Aircraft structures for engineering students, (2014) 1-26.

45. Wang G, Li J, Lv K, Zhang W, Ding X, Yang G, et al. Surface thermal oxidation on titanium implants to enhance osteogenic activity and in vivo osseointegration. Scientific Reports 6(1) (2016) $1-13$.

46. Atmospheric Corrosion of Aluminum Alloys. Total Materia, (2014).

47. Aluminium - Grades, Formability, Fabrication and Finishing. Aalco Metals Limited, Wednesbury, Great Britain, (2005).

48. Mapelli C, Venturini R, Tagliabue C. Extrusion simulation of TI-6AL-4V for the production of special shaped cross sections. Metallurgical Science and Tecnology, 22(2) (2013) 14-20.

49. Sheppard T. Extrusion of aluminium alloys. Springer Science and Business Media, (1999).

50. Boyer RR, Cotton J.D, Mohaghegh M, Schafrik R.E. Materials considerations for aerospace applications. MRS Bulletin, 40(12) (2015) 1055-65.

51. Titanium Alloy: Ti-6Al-4V. Hebei Metals Industrial Limited, China (2016).

52. AFG. Aluminium recycling - processes. Alum Futur Gener, 44(0) (2016) 0-3.

53. Global Aluminium Recycling : A cornerstone of sustainable development. International Aluminum Institute, (2009) 1-36.

54. Aluminium Alloy: Introduction to Aluminium and its Alloys. Aalco Metals Ltd. Wednesbury, (2019).

55. Recycling stainless steel and aluminium: which has higher market value? Melbourne Metal Recycling, (2019).

56. Mitropolskaya N, Briggs R. Boeing: The quest for stronger, cheaper titanium alloys. Boeing Innovation Quarterly, (2018).

57. Knight C. Titanium recycling gives Europe a valuable new metal supply. Medium, 2018.

58. Alexopoulos N.D, Migklis E, Stylianos A, Myriounis D.P. Fatigue behavior of the aeronautical AlLi (2198) aluminum alloy under constant amplitude loading. International Journal of Fatigue, 56 (2013) 95-105.

59. Sujata M, Madan M, Raghavendra K, Bhaumik SK. Fretting fatigue in aircraft components made of Ti-Al-V alloys. Procedia Engineering, 55 (2013) 481-486.

60. Sen I, Gopinath K, Datta R, Ramamurty U. Fatigue in Ti-6Al-4V-B alloys. Acta Materialia, 58(20) (2010) 6799-6809.

61. Wanhill R.J.H, Barter S.A. Executive summary (2009). www.nlr.nl. 